\section{SP3-27 RACE AND ACCESS TO PRENATAL CARE IN BRAZIL}

doi:10.1136/jech.2011.1429760.27

${ }^{1} \mathrm{R}$ Guimarães, ${ }^{*} \mathrm{G}$ Marinho, ${ }^{2} \mathrm{~S}$ Junior, ${ }^{2} \mathrm{~L}$ Santos, ${ }^{2} \mathrm{~T}$ Pinheiro, ${ }^{2} \mathrm{P}$ Herculano. ${ }^{1}$ Federal University of Rio de Janeiro, Institute of Studies in Public Health, Rio de Janeiro, Brazil; ${ }^{2}$ Federal University of Rio de Janeiro, Rio de Janeiro, Brazil

Objective To measure the correlation of race/ethnicity in Brazil with coverage of prenatal consultations, taking into account the races: white, brown and black.

Materials and Methods This is an ecological descriptive study whose premise is that there is a correlation between the ethnic composition of population and quantitative coverage of antenatal care of pregnant women in the population of Brazil. The data were analysed using the coefficient of determination $\left(\mathrm{R}^{2}\right)$ and a linear trendline for the correlation. We estimated the data of the population white, black and brown, and eventually, joining the black and mulatto population, all in proportion.

Results The outcome of the graphs showed a positive correlation between coverage of adequate prenatal and increase the proportion of white population and a similar behaviour with respect to blacks. However, the mixed population to be assessed in that aspect, showed a negative correlation. By joining the black and brown has a negative correlation, however.

Conclusion It was clear how far in Brazil there are racial and socioeconomic inequalities, which play an important role in the right of access to population health.

\section{SP3-28 IS VACCINATION AGAINST THE HUMAN PAPILLOMAVIRUS FOR PREVENTION OF THE CERVIX UTERI CANCER INDICATED IN PAKISTAN WHERE THERE IS NO PAP SMEAR CERVICAL CANCER SCREENING PROGRAM-A PUBLIC HEALTH PERSPECTIVE?}

doi:10.1136/jech.2011.1429760.28

F Badar, ${ }^{*}$ N Anwar. Shaukat Khanum Memorial Cancer Hospital and Research Center, Lahore, Punjab, Pakistan

Introduction As reported by Globocan, in 2008, per 100000 females: (I) in Pakistan, the estimates for cervical cancer were: (i) incidence 19.5 (11 688 cases) and (ii) mortality 12.9 (7311 deaths); and (II) in very high incidence regions as sub-saharan Africa, the annual agestandardised incidence rate was up to 56 and mortality was 41 . Pakistan does not have a Pap smear cervical cancer screening program. The cervical Human Papilloma Virus (HPV) prevalence in women with normal cytology has been reported to be as follows: globally 11.7\%; sub-saharan Africa 24\%; Eastern Europe 21.4\%; and Latin America 16\%. Worldwide, the five most common HPV types were: $16,18,52,31$, and 58.

Method A review was conducted to estimate the prevalence of HPV in cervical tissues obtained from neoplastic and non-neoplastic samples and indications for vaccination of females against HPV infection in Pakistan.

Results Recent studies from Pakistan have shown the HPV 16/18 prevalence in the general population to be about $2.8 \%(\mathrm{~N}=899$ married women, 15-59 years); few other studies have shown the HPV prevalence in cervical cancer to be $18 \%-98 \%(\mathrm{~N}=50-91)$.

Conclusion Information about the prevalence of HPV infection in neoplastic and non-neoplastic samples is sparse. Pakistan does not have a cervical cancer screening program either. More epidemiologic studies are needed to determine if ours is a low- vs a high-HPVprevalence setting and to identify cervical cancer risk factors, before vehemently advocating the adoption of preventive measures against HPV infection using the HPV vaccine, as has been initiated in the country.

\section{SP3-29 PREVALENCE OF STRESS REACTION AMONG TELEMARKETERS AND PSYCHOSOCIAL ASPECTS RELATED TO OCCUPATION}

doi:10.1136/jech.2011.1429760.29

${ }^{1,2}$ A C Santos, ${ }^{*}{ }^{1}$ M I Vianna. IInstituto de Saúde Coletiva, Salvador, Bahia, Brazil; ${ }^{2}$ Universidade do Estado da Bahia, Salvador, Bahia, Brazil, ${ }^{3}$ Faculdade de Odontologia UFBA, Salvador, Bahia, Brazil

Introduction It is estimated that in Brazil there are about 665000 telemarketers, following a strong international requirement, which has built thousands of workers in recent years. The workers main complaints relate to unfavourable working conditions including strict demands on time and productivity, causing anxiety, stress and fatigue. The pathogenic potential of working conditions in telemarketing centres translates into a major public health problem. So the aim of this study was to describe the prevalence of stress reaction among telemarketers and psychosocial aspects related to the occupation

Method This is a cross-sectional study, conducted in attendants in a telemarketing company. We used the scale and demand control and the GHO 12

Results 200 of he 400 call centre workers agreed to participate. Characteristics of the sample: women $(73.5 \%)$, single (84.0\%), black $(52.0 \%)$, aged 24 years $(51.5 \%$, range $18-49$ years), incomplete higher education $(43.0 \%)$ and family income ranging between one and three minimum wages (42.0\%). According to the occupational characteristics, the attendants worked in this business for over 7 months $(56.0 \%)$ carrying fewer than 82 calls/day $(59.0 \%)$ and average service time $>3 \mathrm{~min}$ (97\%). Occupational activity was considered stressful by $68 \%$ and $60 \%$ identified a relationship between symptoms and work.

Conclusion The telemarketers have high levels of stress. There is a suspicion of minor mental disorders, but only in few had definite signs.

\section{SP3-30 CHARACTERISTICS OF ATTEMPTED SUICIDE PATIENTS PRESENTING TO SECONDARY AND TERTIARY EMERGENCY ROOMS, TOCHIGI PREFECTURE, JAPAN}

doi:10.1136/jech.2011.142976o.30

${ }^{1}$ I Chihara, ${ }^{2} Y$ Kudo, ${ }^{1} S$ Tsuboi, ${ }^{1} A$ Sadakane, ${ }^{1} Y$ Aoyama, ${ }^{1} \mathrm{R}$ Ae, ${ }^{1} \mathrm{~T}$ Enkh-Oyun, ${ }^{1} \mathrm{~K}$ Kotani, ${ }^{1} \mathrm{R}$ Uehara, ${ }^{1} \mathrm{Y}$ Nakamura. ${ }^{1}$ Jichi Medical University, Shimotsuke City, Tochigi, Japan; ${ }^{2}$ Keio University, Shinjuku-ku, Tokyo, Japan

Introduction Suicide rate has increased dramatically in Japan since 1998. It is important to reveal the characteristics of attempted suicide patients at emergency rooms (ERs) to prevent future suicides. Methods Questionnaires were sent to all 74 secondary and tertiary ERs in Tochigi prefecture. Data were collected for attempted suicide patients who presented in September 2009.

Results All ERs responded to the survey. Only nine ERs had psychiatric departments. There were 81 attempted suicides (36 men, 45 women). $43 \%$ were in their 20 s or 30 s. Approximately half $(47 \%)$ were unemployed. The majority $(85 \%)$ resided with other family members. The average number of patients presenting to ERs were 3.2 for workdays and 1.6 for weekends/holidays. The most common method of suicide attempt was drug overdose $(57 \%)$ followed by stabbing (18\%), hanging (8\%), and jumping from height (8\%). Half (49\%) used prescription drugs to commit suicide. The majority (59\%) had presented to psychiatric departments, 38\% had a history of depressive disorders in the past, and a quarter had previous suicide attempt. About half (47\%) were admitted to medical or surgery departments, 33\% were discharged home, and 9\% died. After excluding those who died, $46 \%$ were not referred to a psychiatrist, and $39 \%$ were confirmed to have seen a psychiatrist. 
Conclusion Although attempted suicide patients should be referred for psychiatric assessment, many of them were not. It is important to strengthen the chain of care as well as to educate health providers and family members to prevent repeated suicide attempts.

\section{SP3-31 DETERMINANT FACTORS CONTRIBUTION TO THE DEATH OF INDONESIAN HAJJ PILGRIMS FOR THE AGES OF > 40 YEARS IN MECCA, SAUDI ARABIA}

doi:10.1136/jech.2011.1429760.31

N Kodim.* University of Indonesia, Jakarta, Indonesia

Introduction The mortality rate Indonesian Hajj Pilgrims is higher than Indonesian population mortality. The mortality rate of Indonesian hajj pilgrims fluctuated ranging from 2 to 3.8 per 1000 hajj. Methods and Materials This research conducted to the 149537 ordinary hajj pilgrims. Design of the study was cross-sectional ecological studies. Analysis was done using multilevel logistic regression.

Results Factors that contribute to mortality of Indonesian hajj pilgrims are age, sex, educational level, length of stay and preexisting diseases. The factors with the highest contributions to mortality were age $60-69$ years $(36.4 \%)$, age $>79$ years $(30.0 \%)$. male $(27.6 \%)$ and low education $(29.0 \%)$. Pre-existing disease contributed $<6 \%$ to the death rate. Adjusted real per capita expenditure, no access to health facilities adult literacy, populations with health problems and populations self medicating contributed to mortality of Indonesian hajj pilgrims after controlling for other variables.

Conclusions It appears safer for Moslems to go to Mecca before age 50 years. We would suggest paying increased attention to the Hajj pilgrims $>50$ years old, males, those that are thin, those who have lung diseases, metabolic problems or cardio-cerebrovascular and those who flight in the second turn. Further research is needed about the cause of death of Hajj pilgrims in order to assess the effects of environment conditions in Saudi Arabia on Indonesian Hajj pilgrims.

\section{SP3-32 NUTRITIONAL CORRELATES OF EXCESS WEIGHT AMONG ADOLESCENTS}

doi:10.1136/jech.2011.1429760.32

${ }^{1,2} \mathrm{Z}$ Afifi, ${ }^{*} \mathrm{H}$ Hassan, ${ }^{2} \mathrm{O}$ El-Mahgoub, ${ }^{3,4} \mathrm{~A}$ El-Sayed. ${ }^{1}$ College of Medicine, King Faisal University, Al Ahsa, Eastern province, Saudi Arabia; ${ }^{2}$ Faculty of Medicine, Cairo University, Cairo, Egypt; ${ }^{3}$ National Nutrition Institute, $\mathrm{MOH}$, Cairo, Egypt; ${ }^{4} \mathrm{MOH}, \mathrm{Al}$ Kasim, Saudi Arabia

Introduction This study was carried to study the nutritional correlates of excess weight among adolescent scholars.

Methods Two-phase study, a case finding survey followed by case control study. The survey was carried out in 4 schools in Cairo. It included 1551 students. Weight and height were measured. We classified them according to the WHO BMI cut-offs into excess weight (EWG) and normal weight (NWG) groups. Two stratified random samples, 151 each were selected from the two groups. We enquired about the nutritional knowledge, attitudes, self efficacy and dietary practices (24-h recall and Semi-quantitative-food frequency) in the two groups. The schools' nutrition service was assessed.

Results Overall prevalence of excess weight was 30.2\% (obesity $11.6 \%$ and overweight $18.6 \%$ ). The rate was slightly higher in females than in males ( $33.3 \%$ vs $27.2 \%$ respectively). EWG had lower mean scores of nutritional knowledge and sound dietary beliefs. Lower percentage of EWG knew about the causes of obesity, were satisfied with their current weight or had self efficacy $(p=0.000)$. One third tried to decrease weight previously and recently. Higher percentage EWG consumed $>100 \%$ RDA of protein and total energy; $>300 \mathrm{mg}$ cholesterol $(p=0.000)$. They consumed all food groups more frequently except fruits. Higher percentage had lots of snacks between meals and when bothered $(p=0.000$ and 0.02). School nutrition service was deficient and favoured the provision of high energy foods.

Conclusion There is a need to improve the knowledge, attitudes and dietary practices in this age group and to improve the nutrition service at school.

\section{SP3-33 MANAGEMENT AND PREVENTION OF DIABETES USING COMMUNITY- AND ICT-BASED PROGRAM IN JAPANESE RURAL COMMUNITIES}

doi:10.1136/jech.2011.142976o.33

${ }^{1} \mathrm{~K}$ Shiwaku, ${ }^{*}{ }^{1,2} \mathrm{~T}$ Hamano, ${ }^{1} \mathrm{M}$ Iwamoto, ${ }^{1} \mathrm{M}$ Yamasaki, ${ }^{1} \mathrm{M}$ Takeda. ${ }^{1}$ Shimane University School of Medicine, Izumo, Japan; ${ }^{2}$ Shimane University, Matsue, Japan

In recent years, there has been rapid growth in non-communicable disease in developing and developed countries. Diabetes has been identified as a healthcare priority by the Japanese government and WHO. The growth in type 2 diabetes (diabetes) is due to increases in the number of people with diabetes associated with increased longevity and lifestyle changes. Approximately $13.5 \%$ of the Japanese population now has either diabetes or impaired glucose tolerance. This high prevalence of diabetes is associated with a significant economic burden, with diabetes accounting for up to $6 \%$ of the total healthcare budget. Living a healthy lifestyle and weight control will go a long way in preventing the risk of diabetes and other related complications. The Shimane Study, which was undertaken in collaboration with rural communities, revealed prevalence of diabetes increased with urbanisation. Residents in the rural communities had few intakes of lipid and protein, and higher exercise by farming, compared to those in local city. We recruited 188 volunteers with prediabetes for the multi-component 3-month health promotion program, covering nutrition, physical activity and supportive group therapy health promotion program from participates of cohort study. All the participants completed the program from December 2009 by supported the Ministry of Economy, Trade and Industry. Improvement of glucose tolerance was remarkable to change their lifestyle in the higher group with HbA1c. We are developing a new community- and ICT-based program from 2010 by supported the Ministry of Internal Affairs and Communications.

\section{SP3-34 THE OVERVIEW AND PROSPECTS OF "JAPAN ECO \& CHILD STUDY" IN FUKUSHIMA}

doi:10.1136/jech.2011.1429760.34

S Yasumura, ${ }^{*}$ K Hashimoto, M Hoshoya, K Fujimori, Y Wakagi. Fukushima Medical University, School of Medicine, Fukushima, Japan

Introduction The Japanese Ministry of the Environment has begun a birth cohort study, Japan Eco \& Child Study, to clarify the influence environmental risks on children (http://www.env.go.jp/chemi/ceh/ index.html). This study will be conducted on 100000 pregnant mothers and their children from across Japan from 2011. Twenty-six areas across Japan offered to participate in this project, and 15 sites, including Fukushima Medical University, were chosen. The purpose of this birth cohort study is to elucidate an important hypothesis: that environmental factors, including the exposure of children from the fetal period to early childhood to chemical compounds, affects pregnancy/reproduction, the incidence of congenital anomalies, mental development, immunology/allergy, and metabolism/endocrine systems. If environmental agents affecting the growth/ 